\title{
Entre la paciencia y la ciencia: la formación de residentes en medicina interna
}

\section{Between patience and science: the training of internal medicine residents}

\author{
Franco Ernesto León-Jiménez ${ }^{1, a}$, José Gustavo Alvarado-Moreno ${ }^{2, b}$ \\ ${ }^{1}$ Hospital Santa Rosa. Piura, Perú. \\ ${ }^{2}$ Hospital Regional de Lambayeque. Chiclayo, Perú. \\ ${ }^{a}$ Médico interni sta, ORCID: https://orcid.org/ 0000-0002-9418-3236 \\ ${ }^{\mathrm{b}}$ Médico internista, ORCID: https://orcid.org/0000-0001-5936-1829
}

An Fac med. 2020;81(4):466-7. / DOI: https://doi.org/10.15381/anales.v81i4.19428

\section{Correspondencia: \\ Franco León Jiménez \\ francoernestole@gmail.com}

Recibido: 11 de enero 2021

Aprobado: 27 de enero 2021

Publicación en línea: 15 de febrero

2021

Conflictos de interés: Los autores declaran no tener conflictos de interés.

Fuente de financiamiento:

Autofinanciado

Citar como: León-Jiménez F, AlvaradoMoreno J. Entre la paciencia y la ciencia: la formación de residentes en medicina interna. An Fac med. 2020;81(4):466-7. DOl: https://doi. org/10.15381/anales.v81i4.19428

\section{Sr. Editor,}

En el trabajo diario en las salas de medicina interna existe una labor cuyos frutos aparecen sólo con el tiempo: la de formar residentes. No sólo es necesario un bagaje de conocimientos y cualidades sino gestionar este valioso recurso humano y obtener de él su máximo desarrollo. No debe entenderse esto como una mera aproximación cuantitativa para generar producción. El concepto de desarrollo va mucho más allá.

Una idea que tratamos de inculcar, inicialmente, a los residentes, es que lo primero son los pacientes; es decir, lo insuficiente que es ajustar su actividad médica solamente a los horarios y sueldos. Si bien es cierto, estos elementos son indispensables e insustituibles, la labor del internista, y en general de toda especialidad, va mucho más allá.

En segundo lugar, es fundamental generar en ellos, pasión por su quehacer diario. La idea de mejorar la vida de alguien, de crear conocimiento, de formar a otros residentes y generar un clima de aprendizaje y camaradería son propuestas atrayentes que a no pocos agradan.

Un tercer punto vital, es el entendimiento que no deben conformarse con ser "uno de tantos". Esto es algo diario y labor de hormiga, pues la rutina, el cansancio, y la repetición de procedimientos pueden ser tentadoras propuestas que pueden traer a la mente del personal en formación, ideas como: "eso yo ya lo sé", "para que más", "todos hacen los mismo". Es aquí donde empieza el punto de quiebre en la formación del internista ${ }^{(1)}$. Fomentar el aprendizaje y aplicación de la medicina basada en evidencias, la toma de decisiones médicas compartidas, los aspectos bioéticos en la toma de decisiones clínicas, la generación, elaboración y publicación de datos locales, son competencias transversales que deben ser fortalecidas desde el primer día cuando recibimos a los ingresantes. Nuestra opinión es que este enfoque holístico muy difícilmente puede ser evaluado teniendo en cuenta las actuales directrices propuestas por el CONAREME (Comisión Nacional de residentado médico) (2). En ellas, no se plasma de manera práctica y a la vez concienzuda cómo formar y valorar al personal en entrenamiento. La elaboración de formatos propios, listas de cotejo, rúbricas y otros instrumentos de medición, si bien toman tiempo, es la manera objetiva de medir lo que enseñamos.

Adicionalmente, y no por ello menos importante, es educar a los residentes en aspectos relacionados al ser humano. Una visión antropológica y ontológica del paciente, del familiar cuidador, de sus determinantes sociales en salud y una perspectiva crítica del sistema de salud, potencian una visión más integral. Ello principalmente en relación a enfermedades en las que la anamnesis y la psiquis de la persona, juegan un rol fundamental; los trastornos somatomorfos, la fibromialgia, y el síndrome de intestino irritable son claros ejemplos de ello ${ }^{(3)}$. La consulta externa es un escenario donde ello es frecuente.

Otro aspecto, muchas veces olvidado en las personas que formamos residentes, es la salud mental de los mismos. En una revisión sistemática en la que se incluyeron 26 estudios 
en los que participaron 4624 médicos residentes de diferentes especialidades, se halló que la frecuencia del síndrome de Burnout fue de 35,1\% (IC 95\%: 26,8\% - 43,5\%). En el análisis por grupos, la frecuencia en los médicos residentes de medicina interna fue de $29,4 \%{ }^{(4)}$.

Un valor agregado que estimula a muchos clínicos a seguir con esta labor de formar personas, además del compromi-

Tabla 1. Competencias para el clínico que forma residentes de medicina interna.

Permanecer en constante estudio y actualización

Incremento de posibilidades de investigación

Oportunidades de aprendizaje en grupo y trabajo en equipo

Oportunidad para mejorar las capacidades de gestión y liderazgo

Lectura crítica de la literatura

Oportunidad para la elaboración de protocolos de manejo clínico

Desarrollo de habilidades sociales de comunicación

Desarrollo de habilidades en ética y bioética so percibido por ellos, es la adquisición progresiva y satisfactoria de algunas competencias que se describen en la tabla 1.

Las competencias son los desafíos que enfrentan los formadores. La presencia de un sílabo-sí es que lo hay-, ¿̇permitirá homogenizar la formación del residente?, ¿puede un clínico con eminente formación hospitalaria aplicar y evaluar eficientemente a personas en formación?

Estas son preguntas que creemos, aún, no tienen respuesta.

En este punto cabe reflexionar quién es el responsable de evaluar la calidad de las personas que ejercerán esta ardua labor: ¿la universidad?, ¿el colegio médico?, ¿el Ministerio de Salud ?, ¿los servicios hospitalarios de medicina interna? ¿ंel CONAREME?. El reconocimiento (no sólo económico) de quienes realizan esta noble labor escapa a la reflexión que se intenta hacer en estas líneas, pero debe mencionarse y tenerse en cuenta. La generación espontánea del conocimiento/competencia y la consideración de que todos los que inician este itinerario de formación, saldrán con las competencias necesarias, es una visión muy primitiva ${ }^{(5)}$.

Consideramos que el programa de medicina interna, así como otros en el país, deben fortalecerse desde la concepción de la competencia, la búsqueda de la excelencia, la evaluación permanente y la selección idónea de quienes serán los clínicos del futuro.

\section{REFERENCIAS BIBLIOGRÁFICAS}

1. Vera-Delgado A. Humanismo y medicina, y algunas reflexiones pertinentes. Revista Colombiana de Cardiologia. 2004;11(6):270-276.

2. CONAREME [Internet]. Estándares minimos de formación. [Fecha de acceso: 25 de noviembre 2019].
Disponible en: https://www.conareme.org.pe/web/ estandares-de-formacion-CONAREME.php

3. Acuña $F$, Capitán $V$, León $F$. Knowledge on Fi bromyalgia Among General Practitioners, From Chiclayo-Peru, 2016. Reumatología Clínica. 2017;13(6): 326-330. DOI: 10.1016/j.reumae.2016.08.005

4. Ishak WW, Lederer S, Mandili C, Nikravesh R,
Seligman L, Vasa M, et al. Burnout During Residency Training: A Literature Review. J Grad Med Educ. 2009;1(2):236-42. DOI: 10.4300/JGMED-09-00054.1

5. León-Jiménez Franco. Residencia en medicina interna: ¿estamos preparados?. Rev Exp Med 2016;2(3):108-109. 